\title{
Defining Radioiodine-Refractory Differentiated Thyroid Cancer: Efficacy and Safety of Lenvatinib by Radioiodine-Refractory Criteria in the SELECT Trial
}

\author{
Naomi Kiyota, Bruce Robinson, Manisha Shah,, Ana O. Hoff, Matthew H. Taylor, \\ Di Li, ${ }^{6}$ Corina E. Dutcus, ${ }^{6}$ Eun Kyung Lee, Sung-Bae Kim, and Makoto Tahara ${ }^{8}$
}

Background: While there is a clear consensus for defining radioiodine-refractory differentiated thyroid cancer (RR-DTC), it is unknown whether these criteria are equally valid for determining when radioiodine (RAI) therapy is no longer beneficial and systemic treatment should be considered. Lenvatinib, a multikinase inhibitor, significantly prolonged progression-free survival (PFS) compared to placebo in a Phase 3 trial in RR-DTC (SELECT; hazard ratio [HR]: 0.21 [99\% confidence interval (CI) $0.14-0.31$ ]; $p<0.001$ ). This sub-analysis compared clinical outcomes of lenvatinib-treated patients in SELECT stratified by RR-DTC inclusion criteria.

Methods: In SELECT, patients with measurable RR-DTC and radiologic evidence of disease progression $\leq 13$ months prior to study entry were randomized 2:1 to lenvatinib $(24 \mathrm{mg} / \mathrm{day} ; 28$-day cycle) or placebo. In this analysis, patients were stratified based on the following RR-DTC inclusion criteria: no RAI uptake, disease progression within 12 months of RAI therapy despite RAI avidity at the time of treatment, and extensive $(>600 \mathrm{mCi})$ cumulative RAI exposure. All had disease progression as an inclusion criterion for SELECT.

Results: Of 392 patients (261 lenvatinib; 131 placebo) enrolled, 275, 235, and 73 patients met the inclusion criteria for no RAI uptake, disease progression despite RAI avidity, and extensive RAI exposure, respectively. There was significant overlap between the patient groups, with $167(42.6 \%)$ patients meeting more than one inclusion criterion. Lenvatinib improved median PFS compared to placebo in all groups ("no RAI uptake": lenvatinib not quantifiable [NQ; CI 14.8-NQ] vs. placebo, 3.7 months [CI 2.5-5.3]; "disease progression despite RAI avidity": lenvatinib 16.5 months [CI 12.8-NQ] vs. placebo, 3.7 months [CI 1.9-5.4]; "extensive RAI exposure": lenvatinib 18.7 months [CI 10.7-NQ] vs. placebo, 3.6 months [CI 1.9-5.5]). Objective response rates were $71.8 \%, 60.0 \%$, and $56.0 \%$ for patients with no RAI uptake, disease progression despite RAI avidity, and extensive RAI exposure, respectively. Lenvatinib-related adverse events were similar across groups.

Conclusions: Comparable efficacy and safety profiles were observed in lenvatinib-treated patients regardless of RR-DTC criteria, possibly because of a large overlap among patients fulfilling each criterion. However, differing definitions for RR-DTC may be equally valid because both lenvatinib and placebo arms exhibited similar PFS outcomes across groups.

Keywords: lenvatinib, thyroid cancer, multitargeted kinase inhibitor, Phase 3, radioiodine therapy

\footnotetext{
${ }^{1}$ Department of Medical Oncology and Hematology, Kobe University Hospital and Kobe University Hospital Cancer Center, Kobe, Japan.

${ }^{2}$ Kolling Institute of Medical Research, University of Sydney, New South Wales, Australia.

${ }^{3}$ Department of Internal Medicine, The Ohio State University Comprehensive Cancer Center, Columbus, Ohio.

${ }^{4}$ Department of Endocrinology, Endocrine Oncology Unit, Instituto do Cancer do Estado de São Paulo, Universidade de São Paulo, São Paulo, Brazil.

${ }^{5}$ Knight Cancer Institute, Oregon Health and Science University, Portland, Oregon.

${ }^{6}$ Eisai, Inc., Woodcliff Lake, New Jersey.

${ }_{8}^{7}$ Center for Thyroid Cancer, National Cancer Center, Goyang, South Korea.

${ }^{8}$ Asan Medical Center, University of Ulsan College of Medicine, Seoul, South Korea.

${ }^{9}$ Division of Head and Neck Medical Oncology, National Cancer Center Hospital East, Kashiwa, Japan.

(C) Naomi Kiyota et al. 2017; Published by Mary Ann Liebert, Inc. This is an Open Access article distributed under the terms of the Creative Commons Attribution License, which permits unrestricted use, distribution, and reproduction in any medium, provided the original work is properly cited.
} 


\section{Introduction}

A PPROXIMATELY 90\% OF ALL thyroid cancers are differentiated thyroid cancer, which is typically treated with surgery in the first instance, followed by ablation of the thyroid remnant with radioiodine (RAI) (1). Approximately four cases per million of the population are refractory to RAI therapy (2). Life expectancy for patients with radioiodinerefractory differentiated thyroid cancer (RR-DTC) is three to six years, with a 10 -year survival rate of $10 \%$ from the time metastatic lesions are detected (2-4).

Patients with RR-DTC have few options if further treatment is needed for metastatic disease, and novel therapeutic strategies are therefore required (3). Tyrosine kinase inhibitors (TKIs) have demonstrated promising results in the treatment of RR-DTC $(3,5)$. Lenvatinib is an oral multikinase inhibitor that targets vascular endothelial growth factor receptors 1-3, fibroblast growth factor receptors (FGFR) 1-4, platelet-derived growth factor receptor-alpha, and RET and KIT proto-oncogenes (6-8). Lenvatinib has been approved for the treatment of patients with RR-DTC in Japan, Europe, and the United States (9), based on the results of the randomized, double-blind, multicenter, Phase 3 Study of (E7080) LEnvatinib in Differentiated Cancer of the Thyroid (SELECT) trial, in which lenvatinib significantly increased progression-free survival (PFS) in patients with RR-DTC compared to placebo (hazard ratio $[\mathrm{HR}]=0.21$ [99\% confidence interval (CI) 0.14-0.31]; $p<0.001$ ) (10).

Patients with RR-DTC often present with clinically heterogeneous lesions (5,10-12). Based on clinical presentation and tumor imaging scans, most patients with RR-DTC fall into one or more of the following categories $(13,14)$ : those with metastatic disease that does not take up RAI at the time of initial treatment; those with tumors that have previously taken up RAI but have lost the ability to do so; those with tumors that retain RAI uptake in only some lesions; those with metastatic disease that progresses despite substantial RAI uptake; and those with disease progression despite receiving $>600 \mathrm{mCi}(22.3 \mathrm{GBq})$ of RAI.

In clinical studies in accordance with the prescribed criteria for RR-DTC, TKIs showed efficacy, but the correlation between each of these categories of RR-DTC and a patient's response to RAI therapy is unclear. Therefore, establishing a common definition for RR-DTC has become increasingly important because clinicians need to recognize the point at which RAI therapy is no longer beneficial to a patient and when to initiate the use of emerging systemic treatment options for this disease setting. This analysis examines the efficacy and safety of lenvatinib in patients with RR-DTC according to the three definitions of RR-DTC used as inclusion criteria in SELECT.

\section{Materials and Methods}

\section{Study design}

The full details of SELECT (ClinicalTrials.gov number NCT01321554) have been previously published (10). Briefly, patients with RR-DTC, measurable disease, and independently reviewed radiologic evidence of disease progression within 13 months prior to study entry were randomized $2: 1$ to receive lenvatinib ( $24 \mathrm{mg} /$ day in a 28 -day cycle) or placebo until disease progression or unacceptable toxicity. Patients were stratified by age ( $\leq 65$ or $>65$ years), geographic region (Europe, North America, or other), and prior TKI treatment (yes or no).
Up to one prior TKI treatment was allowed. The trial had a crossover design that allowed patients who progressed on placebo to be offered open-label treatment with lenvatinib (10).

For the current analysis, patients in SELECT were stratified according to the three RR-DTC inclusion criteria. Patients with one or more measurable lesion that did not demonstrate RAI uptake on any RAI scan were included in the "no RAI uptake" group. Patients with measurable lesions that had progressed within 12 months of RAI therapy per Response Evaluation Criteria in Solid Tumors version 1.1 (RECIST v1.1) (15) despite demonstration of RAI avidity at the time of treatment by pretreatment or posttreatment scanning (these patients were not eligible for possible curative surgical therapy) were included in the "disease progression despite RAI avidity" group. Finally, patients who had received a cumulative activity of RAI $>600 \mathrm{mCi}$ (22 GBq), with the last treatment administered less than six months prior to study entry were included in the "extensive RAI exposure" group (10). It is important to note that patients could be included in multiple categories, and this could obscure differences among the three RR-DTC inclusion criteria groups.

\section{Endpoints and assessments}

The primary endpoint of SELECT was PFS determined by independent radiologic review in the intent-to-treat population. Secondary endpoints included the objective response rate (ORR) comprising complete or partial response according to RECIST v1.1, and overall survival (OS). Survival endpoints were calculated using Kaplan-Meier product-limit estimates and a stratified log-rank test. Calculation of HRs and associated CIs used a Cox proportional hazards regression model stratified by the randomization factors. Response rates were compared using stratified Cochran-MantelHaenszel tests at a two-sided alpha level of 0.05 (10).

Adverse events (AEs) were recorded and assessed according to the National Cancer Institute Common Terminology Criteria for Adverse Events version 4.0 (16). Other safety assessments included symptom and vital signs reporting, hematologic and biochemical laboratory testing, urinalysis, electrocardiography, and echocardiography (including left ventricular ejection fraction) (10).

\section{Results}

SELECT enrolled 392 eligible patients from 21 countries (the Americas, Europe, Asia, and Australia) between August 2011 and October $2012(10,17)$. The cutoff date for the primary data analysis was November 15, 2013. The median follow-up at this time was 17.1 months for patients who received lenvatinib and 17.4 months for patients on placebo.

\section{Patient groups and characteristics}

Of the 392 patients enrolled in SELECT (261 lenvatinib, 131 placebo), 275 patients met the inclusion criteria for "no RAI uptake," 235 for "disease progression despite RAI avidity," and 73 for "extensive RAI exposure" (Table 1). All patients had disease progression as an inclusion criterion in SELECT. Baseline characteristics were similar across groups, with the exception of median RAI activity received, which was higher in the "extensive RAI exposure" group (Table 1). A total of 167 (42.6\%) patients met more than one RR-DTC criterion and were therefore included in multiple groups (Fig. 1). The greatest 
Table 1. Baseline and Demographic Characteristics by RR-DTC Inclusion Criteria

\begin{tabular}{|c|c|c|c|c|c|c|}
\hline & \multicolumn{2}{|c|}{ No RAI uptake } & \multicolumn{2}{|c|}{$\begin{array}{l}\text { Disease progression } \\
\text { despite RAI avidity }\end{array}$} & \multicolumn{2}{|c|}{$\begin{array}{l}\text { Extensive RAI } \\
\text { exposure }\end{array}$} \\
\hline & $\begin{array}{l}\text { Lenvatinib } \\
(\mathrm{n}=174)\end{array}$ & $\begin{array}{l}\text { Placebo } \\
(\mathrm{n}=101)\end{array}$ & $\begin{array}{l}\text { Lenvatinib } \\
(\mathrm{n}=155)\end{array}$ & $\begin{array}{l}\text { Placebo } \\
(\mathrm{n}=80)\end{array}$ & $\begin{array}{l}\text { Lenvatinib } \\
(\mathrm{n}=50)\end{array}$ & $\begin{array}{l}\text { Placebo } \\
(\mathrm{n}=23)\end{array}$ \\
\hline Age, years, median (range) & $63(27-89)$ & $62(21-81)$ & $64(27-89)$ & $62(40-81)$ & $63(27-83)$ & $60(46-74)$ \\
\hline \multicolumn{7}{|l|}{ Sex, $n(\%)$} \\
\hline $\begin{array}{l}\text { Male } \\
\text { Female }\end{array}$ & $91(52.3)$ & $57(56.4)$ & $76(49.0)$ & $48(60.0)$ & $19(38.0)$ & $13(56.5)$ \\
\hline $\begin{array}{l}\text { Region, } n(\%) \\
\text { Europe }\end{array}$ & \multicolumn{5}{|c|}{ Region, $n(\%)$} & \\
\hline North America & $46(26.4)$ & $29(28.7)$ & $44(28.4)$ & $18(22.5)$ & $14(28.0)$ & $6(26.1)$ \\
\hline Asia $^{a}$ & $27(15.5)$ & $14(13.8)$ & 18 (11.6) & $12(15.0)$ & $7(14.0)$ & $6(26.1)$ \\
\hline \multicolumn{7}{|l|}{ Baseline TSH $(\mu \mathrm{IU} / \mathrm{mL}), n(\%)$} \\
\hline$\leq 0.5$ & $149(85.6)$ & $93(92.1)$ & $132(85.2)$ & $74(92.5)$ & $46(92.0)$ & $23(100.0)$ \\
\hline$>0.5-2.0$ & $17(9.8)$ & $8(7.9)$ & 18 (11.6) & $5(6.3)$ & $2(4.0)$ & 0 \\
\hline$>2.0-5.5$ & $8(4.6)$ & 0 & $5(3.2)$ & $1(1.3)$ & $2(4.0)$ & 0 \\
\hline \multicolumn{7}{|l|}{ ECOG PS, $n(\%)$} \\
\hline 0 & $106(60.9)$ & $56(55.4)$ & $78(50.3)$ & $38(47.5)$ & $24(48.0)$ & $13(56.5)$ \\
\hline 1 & $64(36.8)$ & $43(42.6)$ & 65 (41.9) & $42(52.5)$ & $25(50.0)$ & $9(39.1)$ \\
\hline 2 & $4(2.3)$ & $2(2.0)$ & $11(7.1)$ & 0 & $1(2.0)$ & $1(4.3)$ \\
\hline 3 & 0 & 0 & $1(0.6)$ & 0 & 0 & 0 \\
\hline \multicolumn{7}{|l|}{ Prior VEGF therapy, $n(\%)$} \\
\hline 0 & $128(73.6)$ & $80(79.2)$ & $117(75.5)$ & $64(80.0)$ & $40(80.0)$ & $17(73.9)$ \\
\hline 1 & $46(26.4)$ & $21(20.8)$ & $38(24.5)$ & $16(20.0)$ & $10(20.0)$ & $6(26.1)$ \\
\hline \multicolumn{7}{|l|}{ Histology, $n(\%)$} \\
\hline Papillary & $108(62.1)$ & $72(71.3)$ & $95(61.3)$ & $57(71.3)$ & $30(60.0)$ & 17 (73.9) \\
\hline Poorly differentiated & $17(9.8)$ & $16(15.8)$ & $14(9.0)$ & $11(13.8)$ & $4(8.0)$ & $3(13.0)$ \\
\hline Follicular, not Hürthle cell & $66(37.9)$ & $29(28.7)$ & $60(38.7)$ & $23(28.8)$ & $20(40.0)$ & $6(26.1)$ \\
\hline Hürthle cell & $31(17.8)$ & $14(13.9)$ & $26(16.8)$ & $11(13.8)$ & $4(8.0)$ & $3(13.0)$ \\
\hline $\begin{array}{l}\text { Mean tumor burden } \\
\text { at baseline, mm (range) }\end{array}$ & $68(15-226)$ & $69(15-236)$ & $73(15-331)$ & $74(15-267)$ & $72(15-331)$ & $82(20-143)$ \\
\hline \multicolumn{7}{|c|}{ Time from most recent disease progression to randomization, $n(\%)$} \\
\hline$<3$ months & $142(81.6)$ & $74(73.3)$ & $122(78.7)$ & $54(67.5)$ & $43(86.0)$ & $14(60.9)$ \\
\hline$\geq 3$ months & $28(16.1)$ & $24(23.8)$ & $31(20)$ & $22(27.5)$ & $7(14.0)$ & $8(34.8)$ \\
\hline Missing & $4(2.3)$ & $3(3.0)$ & $2(1.3)$ & $4(5.0)$ & 0 & $1(4.3)$ \\
\hline $\begin{array}{l}\text { Median radioiodine } \\
\text { activity received, GBq }\end{array}$ & $11.1^{\mathrm{b}}$ & $13.0^{\mathrm{c}}$ & $11.8^{\mathrm{d}}$ & $11.4^{\mathrm{e}}$ & 30.6 & 30.1 \\
\hline
\end{tabular}

${ }^{a}$ Asia including Japan, Republic of Korea, and Thailand.

${ }^{\mathrm{b}}$ Data available for 162 patients.

${ }^{\mathrm{c}}$ Data available for 96 patients.

${ }^{\mathrm{d}}$ Data available for 154 patients.

${ }^{\mathrm{e}}$ Data available for 79 patients.

ECOG PS, Eastern Cooperative Oncology Group performance status; GBq, gigabecquerel ( $1 \mathrm{GBq}=27.0 \mathrm{mCi})$; RAI, radioiodine; RRDTC, radioiodine-refractory differentiated thyroid cancer; TSH, thyrotropin; VEGF, vascular endothelial growth factor.

overlap was in the "no RAI uptake" and "disease progression despite RAI avidity" groups, in which 117 (29.8\%) patients qualified for both groups. There was only minor overlap between the "no RAI uptake" and "extensive RAI exposure" groups $(n=6 ; 1.5 \%)$. The number of patients categorized into both the "disease progression despite RAI avidity" and "extensive RAI exposure" groups was slightly higher $(n=19$; $4.8 \%)$. There were $25(6.4 \%)$ patients who met all three RRDTC group criteria. Of the patients enrolled, 224 (57.1\%) met only one RR-DTC inclusion criterion. For the 106 total lenvatinib-treated patients across all groups, $65(61.3 \%)$ were $\leq 65$ years old, $59(55.7 \%)$ had papillary histology, 47 (44.3\%) had follicular histology, 27 (25.5\%) had disease progression or death within six months of randomization, and the median tumor size at baseline was $60.9 \mathrm{~mm}$ (range 15.1-331.2 mm). For the 61 total placebo-treated patients, $39(63.9 \%)$ were $\leq 65$ years old, 48 (78.7\%) had papillary histology, 13 (21.3\%) had follicular histology, $41(67.2 \%)$ had disease progression or death within six months of randomization, and the median tumor size at baseline was $59.9 \mathrm{~mm}$ (range 15.2-236.1 $\mathrm{mm}$ ).

\section{Efficacy}

The efficacy of lenvatinib was maintained in all three groups regardless of the RR-DTC criteria used, with lenvatinib treatment resulting in significantly longer PFS compared to placebo in all three RR-DTC criteria groups (Figs. 2A-C). Notably, in the placebo arms, PFS was similar regardless of RR-DTC inclusion criteria. Median PFS, in months, in the "no RAI uptake" group was not quantifiable (NQ [CI 14.8-NQ]) versus 


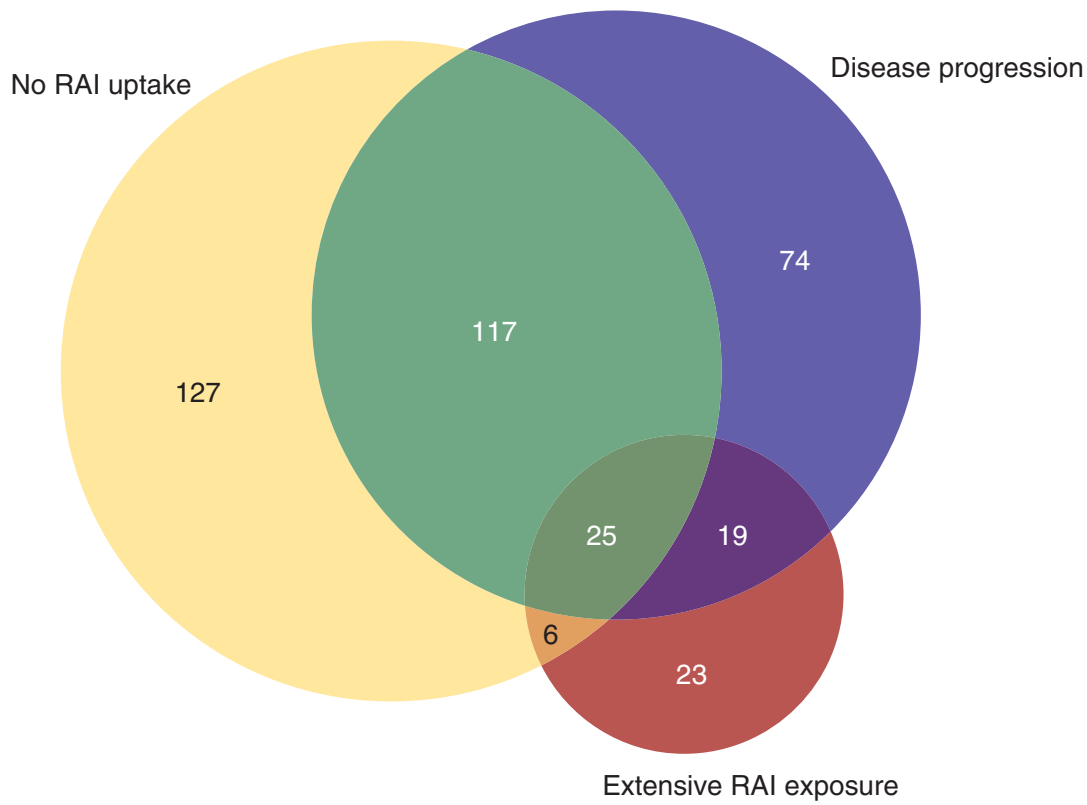

FIG. 1. Venn diagram of patients in SELECT by RR-DTC criteria group. Information is not available for one patient. RAI, radioiodine; RR-DTC, radioiodine-refractory differentiated thyroid cancer; SELECT, Study of (E7080) LEnvatinib in Differentiated Cancer of the Thyroid.
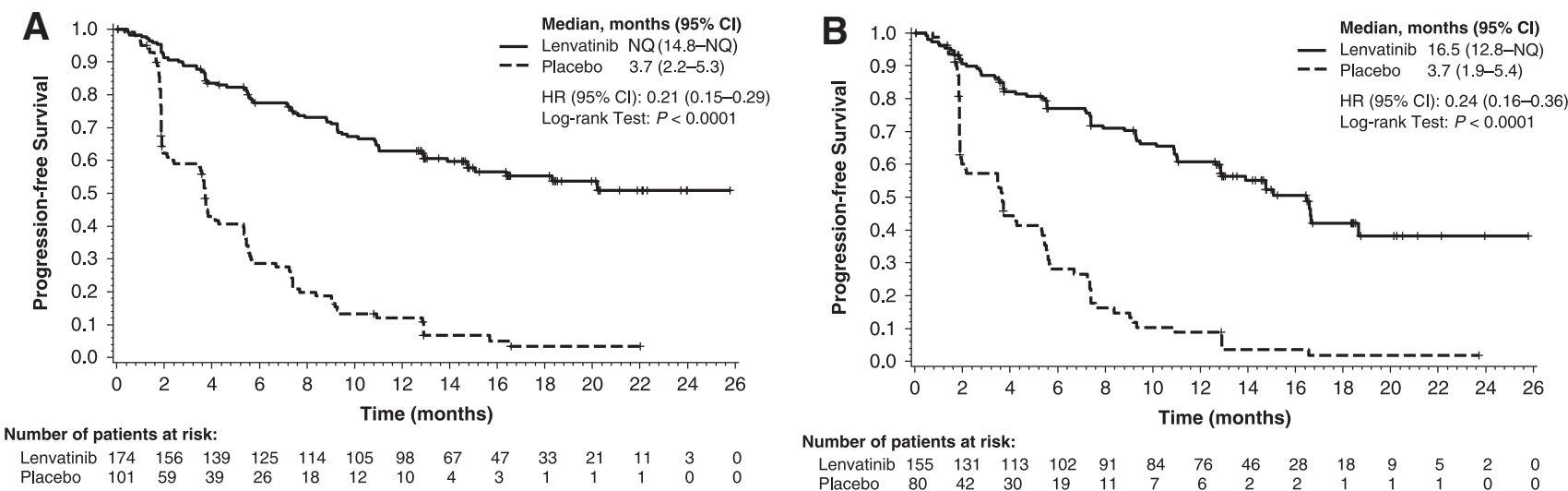

Number of patients at risk:
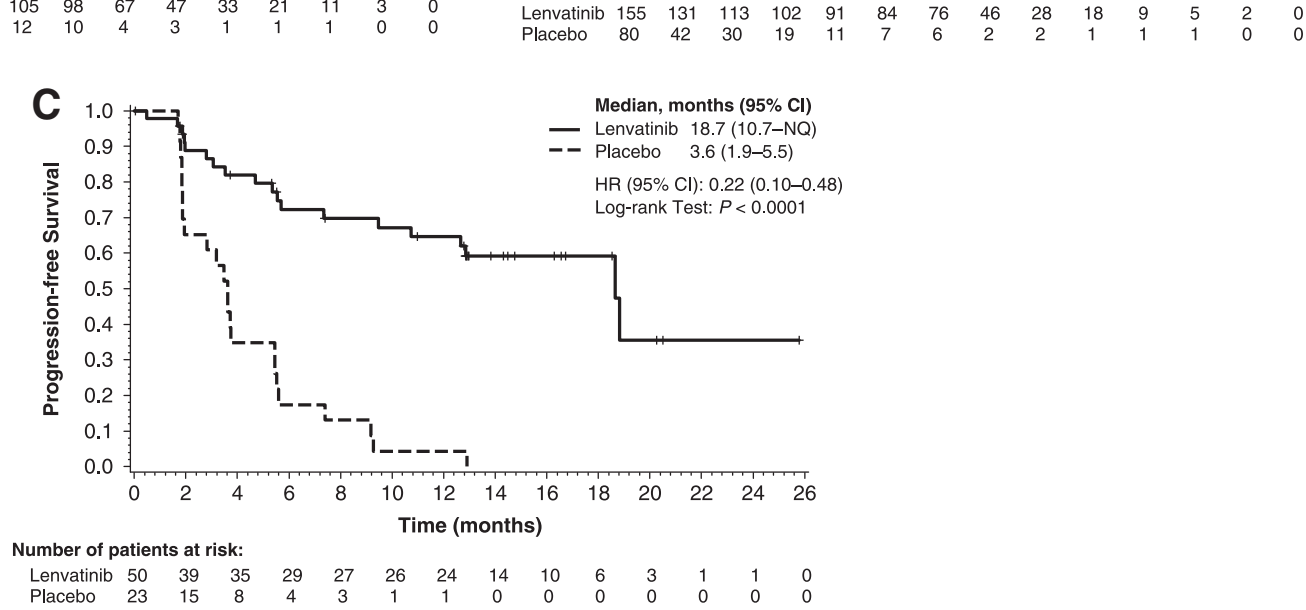

FIG. 2. Kaplan-Meier estimates of progression-free survival by RR-DTC inclusion criteria: (A) no RAI uptake, (B) disease progression, (C) extensive RAI exposure. CI, confidence interval; HR, hazard ratio; NQ, not quantifiable. 
Table 2. Summary of Tumor Response by RR-DTC CRiteria

\begin{tabular}{|c|c|c|c|c|c|c|}
\hline \multirow[b]{2}{*}{ Response, $n(\%)$} & \multicolumn{2}{|c|}{ No RAI uptake } & \multicolumn{2}{|c|}{$\begin{array}{l}\text { Disease progression } \\
\text { despite RAI avidity }\end{array}$} & \multicolumn{2}{|c|}{ Extensive RAI exposure } \\
\hline & $\begin{array}{c}\text { Lenvatinib } \\
(\mathrm{n}=174)\end{array}$ & $\begin{array}{l}\text { Placebo } \\
(\mathrm{n}=101)\end{array}$ & $\begin{array}{l}\text { Lenvatinib } \\
(\mathrm{n}=155)\end{array}$ & $\begin{array}{c}\text { Placebo } \\
(\mathrm{n}=80)\end{array}$ & $\begin{array}{l}\text { Lenvatinib } \\
\quad(\mathrm{n}=50)\end{array}$ & $\begin{array}{l}\text { Placebo } \\
(\mathrm{n}=23)\end{array}$ \\
\hline ORR & $125(71.8)$ & $2(2.0)$ & $93(60.0)$ & $1(1.3)$ & $28(56.0)$ & 0 \\
\hline Best overall response & & & & & & \\
\hline Complete response & $3(1.7)$ & 0 & $2(1.3)$ & 0 & 0 & 0 \\
\hline Partial response & $122(70.1)$ & $2(2.0)$ & $91(58.7)$ & $1(1.3)$ & $28(56.0)$ & 0 \\
\hline Stable disease & $30(17.2)$ & $57(56.4)$ & $41(26.5)$ & $43(53.8)$ & $13(26.0)$ & $13(56.5)$ \\
\hline Progressive disease & $13(7.5)$ & 38 (37.6) & $13(8.4)$ & $33(41.3)$ & $3(6.0)$ & $10(43.5)$ \\
\hline Not evaluable & $1(0.6)$ & $1(1.0)$ & $1(0.6)$ & $1(1.3)$ & 0 & 0 \\
\hline Unknown & $5(2.9)$ & $3(3.0)$ & $7(4.5)$ & $2(2.5)$ & $6(12.0)$ & 0 \\
\hline
\end{tabular}

ORR, objective response rate.

3.7 months [CI 2.5-5.3] in the lenvatinib and placebo arms, respectively. In the "disease progression despite RAI avidity" group, median PFS was 16.5 months [CI 12.8-NQ] for lenvatinib versus 3.7 months [CI 1.9-5.4] for placebo. The median PFS in the "extensive RAI exposure" group also favored lenvatinib (18.7 months [CI 10.7-NQ]) compared to placebo (3.6 months [CI 1.9-5.5]).

The ORRs were $71.8 \%, 60.0 \%$, and $56.0 \%$ for patients receiving lenvatinib in the "no RAI uptake," "disease progression despite RAI avidity," and "extensive RAI exposure" groups, respectively, compared to $2.0 \%, 1.3 \%$, and $0 \%$, respectively, for patients receiving placebo (Table 2). Complete responses were reported for three patients in the "no RAI uptake" group and two patients in the "disease progression, despite RAI avidity" group. No patients receiving placebo reported a complete response (Table 2). At data cutoff, median OS was NQ for any group.

\section{Safety}

Patients in all three overlapping RR-DTC criteria groups received comparable numbers of cycles of lenvatinib treatment (range 14-16 cycles). Dose intensity and duration of lenvatinib treatment were also similar across groups (Table 3 ). The safety profiles were generally comparable between the three RR-DTC criteria groups (Table 4). Almost all patients ( $>96 \%$ ) experienced a lenvatinib-related treatment-emergent adverse event
(TEAE) in each criteria group. The proportions of patients who experienced lenvatinib-related TEAEs of grade $\geq 3$ were also similar across groups, ranging from $73.6 \%$ in the "no RAI uptake" group to $76.0 \%$ in the "extensive RAI exposure" group. Likewise, the proportion of patients who required lenvatinib dose reductions because of TEAEs was comparable between groups at $69.0 \%$ in the "no RAI uptake" group, $63.9 \%$ in the "disease progression despite RAI avidity" group, and $56.0 \%$ in the "extensive RAI exposure" group. Serious AEs were experienced by $44.3 \%$ of patients in the "no RAI uptake" group, $54.2 \%$ of patients in the "disease progression despite RAI avidity" group, and $58.0 \%$ of patients in the "extensive RAI exposure" group. Fatal treatment-related AEs occurred in $1.1 \%$ of patients in the "no RAI uptake" group, $1.3 \%$ of patients in the "disease progression despite RAI avidity" group, and $2.0 \%$ of patients in the "extensive RAI exposure" group.

\section{Discussion}

This analysis demonstrates that the efficacy and safety of lenvatinib was similar regardless of the RR-DTC criteria used to select patients for enrollment in SELECT. PFS, the primary efficacy measure in the original trial, was significantly longer in patients receiving lenvatinib compared to placebo in all three RR-DTC criteria groups. The comparable outcomes observed among the RR-DTC criteria groups suggest that lenvatinib may be effective in treating RR-DTC, irrespective

Table 3. Lenvatinib Exposure and Dose Modification by RR-DTC Criteria

\begin{tabular}{|c|c|c|c|c|c|c|}
\hline \multirow[b]{2}{*}{ Median (range) } & \multicolumn{2}{|c|}{ No RAI uptake } & \multicolumn{2}{|c|}{$\begin{array}{l}\text { Disease progression } \\
\text { despite RAI avidity }\end{array}$} & \multicolumn{2}{|c|}{$\begin{array}{l}\text { Extensive RAI } \\
\text { exposure }\end{array}$} \\
\hline & $\begin{array}{l}\text { Lenvatinib } \\
(\mathrm{n}=174)\end{array}$ & $\begin{array}{l}\text { Placebo } \\
(\mathrm{n}=101)\end{array}$ & $\begin{array}{l}\text { Lenvatinib } \\
(\mathrm{n}=155)\end{array}$ & $\begin{array}{l}\text { Placebo } \\
(\mathrm{n}=80)\end{array}$ & $\begin{array}{l}\text { Lenvatinib } \\
\quad(\mathrm{n}=50)\end{array}$ & $\begin{array}{l}\text { Placebo } \\
(\mathrm{n}=23)\end{array}$ \\
\hline Number of cycles received & $16.0(1-30)$ & $5.0(1-25)$ & $15.0(1-30)$ & $5.0(1-26)$ & $14.0(1-29)$ & $5.0(2-16)$ \\
\hline $\begin{array}{l}\text { Duration of treatment, } \\
\text { months }\end{array}$ & $13.9(0-27)$ & $4.6(0-22)$ & $13.6(0-27)$ & $4.2(1-24)$ & $12.3(0-26)$ & $4.1(2-14)$ \\
\hline $\begin{array}{l}\text { Dose intensity, } \\
\mathrm{mg} / \text { day/patient }\end{array}$ & $17.2(6-24)$ & $24.0(18-24)$ & $17.0(6-25)$ & $24.0(15-24)$ & $17.0(8-24)$ & $24.0(22-24)$ \\
\hline $\begin{array}{l}\text { Received percentage } \\
\text { of planned dose }\end{array}$ & $71.8(24-100)$ & $100.0(75-100)$ & $70.6(26-106)$ & $100.0(61-100)$ & $70.7(31-100)$ & $100.0(92-100)$ \\
\hline
\end{tabular}


Table 4. Treatment-Related Treatment-Emergent Adverse Events (as Assessed by Investigator) OCCURring In $\geq 20 \%$ of Patients in ANy Treatment Group

\begin{tabular}{|c|c|c|c|c|c|c|c|c|c|c|c|c|}
\hline \multirow[b]{3}{*}{ Related TEAE, \% } & \multicolumn{4}{|c|}{ No RAI uptake } & \multicolumn{4}{|c|}{$\begin{array}{l}\text { Disease progression } \\
\text { despite RAI avidity }\end{array}$} & \multicolumn{4}{|c|}{$\begin{array}{c}\text { Extensive } \\
\text { RAI exposure }\end{array}$} \\
\hline & \multicolumn{2}{|c|}{$\begin{array}{l}\text { Lenvatinib } \\
(\mathrm{n}=174)\end{array}$} & \multicolumn{2}{|c|}{$\begin{array}{l}\text { Placebo } \\
(\mathrm{n}=101)\end{array}$} & \multicolumn{2}{|c|}{$\begin{array}{l}\text { Lenvatinib } \\
(\mathrm{n}=155)\end{array}$} & \multicolumn{2}{|c|}{$\begin{array}{l}\text { Placebo } \\
(\mathrm{n}=80)\end{array}$} & \multicolumn{2}{|c|}{$\begin{array}{l}\text { Lenvatinib } \\
\qquad(\mathrm{n}=50)\end{array}$} & \multicolumn{2}{|c|}{$\begin{array}{l}\text { Placebo } \\
(\mathrm{n}=23)\end{array}$} \\
\hline & $\begin{array}{l}\text { Any } \\
\text { grade }\end{array}$ & $\underset{\geq 3}{\text { Grade }}$ & $\begin{array}{l}\text { Any } \\
\text { grade }\end{array}$ & $\underset{\geq 3}{\text { Grade }}$ & $\begin{array}{l}\text { Any } \\
\text { grade }\end{array}$ & $\underset{\geq 3}{\text { Grade }}$ & $\begin{array}{l}\text { Any } \\
\text { grade }\end{array}$ & $\underset{\geq 3}{\text { Grade }}$ & $\begin{array}{l}\text { Any } \\
\text { grade }\end{array}$ & $\underset{\geq 3}{\text { Grade }}$ & $\begin{array}{l}\text { Any } \\
\text { grade }\end{array}$ & $\underset{\geq 3}{\text { Grade }}$ \\
\hline Any related TEAE & 96.6 & 73.6 & 58.4 & 9.9 & 96.8 & 74.8 & 56.3 & 10.0 & 98.0 & 76.0 & 34.8 & 0 \\
\hline Hypertension & 66.7 & 41.4 & 10.9 & 2.0 & 67.7 & 40.0 & 10.0 & 3.8 & 66.0 & 38.0 & 4.3 & 0 \\
\hline Diarrhea & 65.5 & 8.0 & 7.9 & 0 & 53.5 & 7.7 & 10.0 & 0 & 46.0 & 2.0 & 0 & 0 \\
\hline Decreased weight & 44.8 & 6.3 & 8.9 & 0 & 49.7 & 11.0 & 10.0 & 0 & 56.0 & 12.0 & 0 & 0 \\
\hline Decreased appetite & 47.1 & 2.9 & 11.9 & 0 & 52.9 & 6.5 & 11.3 & 0 & 48.0 & 6.0 & 4.3 & 0 \\
\hline Nausea & 39.1 & 1.7 & 13.9 & 1.0 & 45.2 & 2.6 & 13.8 & 0 & 38.0 & 0 & 4.3 & 0 \\
\hline Fatigue & 38.5 & 2.3 & 19.8 & 1.0 & 38.1 & 6.5 & 16.3 & 1.3 & 34.0 & 4.0 & 8.7 & 0 \\
\hline Stomatitis & 36.2 & 2.9 & 5.0 & 0 & 34.2 & 5.8 & 5.0 & 0 & 38.0 & 10.0 & 0 & 0 \\
\hline Proteinuria & 33.3 & 10.3 & 2.0 & 0 & 30.3 & 9.0 & 1.3 & 0 & 14.0 & 4.0 & 0 & 0 \\
\hline Vomiting & 28.2 & 1.7 & 5.9 & 0 & 32.9 & 2.6 & 8.8 & 0 & 28.0 & 0 & 0 & 0 \\
\hline $\begin{array}{l}\text { Palmar-plantar } \\
\text { erythrodysesthesia } \\
\text { syndrome }\end{array}$ & 31.0 & 3.4 & 1.0 & 0 & 29.0 & 2.6 & 1.3 & 0 & 26.0 & 2.0 & 0 & 0 \\
\hline Headache & 28.7 & 2.3 & 5.9 & 0 & 25. & 3.2 & 6.3 & 0 & 16 & 0 & 0 & 0 \\
\hline Dysphonia & 25.9 & 1.1 & 3.0 & 0 & 23.9 & 1.3 & 5.0 & 0 & 26.0 & 0 & 0 & 0 \\
\hline Asthenia & 23.6 & 3.4 & 9.9 & 1.0 & 20.6 & 4.5 & 10.0 & 1.3 & 14.0 & 2.0 & 4.3 & 0 \\
\hline Arthralgia & 20.1 & 0 & 0 & 0 & 14.2 & 0 & 1.3 & 0 & 10.0 & 0 & 0 & 0 \\
\hline Dysgeusia & 16.7 & 0 & 2.0 & 0 & 18.1 & 0 & 1.3 & 0 & 20.0 & 0 & 0 & 0 \\
\hline
\end{tabular}

TEAE, treatment-emergent adverse event.

of the criteria used to define the parameters of the radioiodine refractoriness. Likewise, patients in all three groups were similarly tolerant of the treatment, with little variation in the safety outcomes between the three RR-DTC groups. It is important to note that there was a large number of patients who satisfied the criteria for more than one RRDTC group, including nearly $30 \%$ of patients who fulfilled both the "no RAI uptake" and "disease progression despite RAI avidity" criteria, which likely influenced the comparable efficacy and safety profiles between RR-DTC criteria groups. In addition, all patients in SELECT had disease progression, and this is a major confounding factor in this analysis.

The three RR-DTC criteria used in this study have been used in a number of other studies $(11,14,18)$. However, the criteria have been considered unsatisfactory by some researchers, as the RAI activity given per treatment has often been undefined in studies, leading to uncertainty as to whether the activity was truly in the therapeutic range or if, in fact, radioiodine-refractory properties were defined based on lack of response to sub-therapeutic RAI activity (19). The maximum cumulative RAI activity $(600 \mathrm{mCi}$ or $22 \mathrm{GBq}$ ) is somewhat arbitrary and is based on studies that showed that cumulative activity $>600 \mathrm{mCi}$ increased the risk of secondary cancers but was unlikely to be associated with complete responses $(4,14,19)$. It is possible that a patient classified with RR-DTC using these criteria may in fact not be refractory to RAI at all, and some authors have argued that the total cumulative RAI activity should be based on toxicity and efficacy in individual patients rather than on broad guidelines (20).
Disease progression, despite RAI treatment, has been identified as an important indication for starting a patient on a TKI, as differentiated thyroid cancer follows a generally indolent path (5). Initiation of treatment with a TKI should be done in order to achieve a specific patient-related outcome, such as tumor response or symptom control, and with due consideration of toxicity risks (5). Notably, lenvatinib also demonstrated activity in patients who had already progressed after receiving a different TKI, possibly because of lenvatinib inhibiting a unique set of kinase receptors, including FGFRs (10). The present analysis suggests that lenvatinib may also be effective, irrespective of the RR-DTC criteria used to identify radioiodinerefractory patients who showed disease progression within the previous 13 months. This disease progression requirement for inclusion in the study may also contribute to similarities in PFS among patients treated with lenvatinib presented here.

In conclusion, this analysis demonstrates that lenvatinibtreated patients experience comparable efficacy and safety profiles regardless of RR-DTC criteria used. These results may indicate that differing definitions for RR-DTC are equally valid for selection for lenvatinib therapy.

\section{Acknowledgments}

The authors thank the patients, their families, the investigators, and the teams who participated in this trial. This study was funded by Eisai, Inc. Editorial assistance was provided by Oxford PharmaGenesis, Inc., and was funded by Eisai, Inc. This article was previously presented in part at the 18th European Cancer Congress (ECC) Annual Meeting, Vienna, Austria, September 25-29, 2015. 


\section{Author Disclosure Statement}

N.K. received honoraria and grant support from Eisai, Inc., and received research funding from ONO, and BoehringerIngelheim Japan. B.R. served as an advisory board member for Eisai, Inc. M.S. received grants from Exelixis, Eisai, Inc., Bayer. A.O.H. received research funding from Eisai, Inc. M.H.T. received consulting/honoraria from Eisai, Inc., and ONYX. D.L. is an employee of Eisai, Inc. C.E.D. is an employee of Eisai, Inc. E.K.L. served as an advisory board member for Eisai, Inc. S.-B.K. received research funding from Novartis, Kyowha Kirin. M.T. received grants/fees from Eisai, Inc., Boehringher-Ingelheim, and honoraria from MerckSerono, and BMS.

\section{References}

1. Cooper DS, Doherty GM, Haugen BR, Kloos RT, Lee SL, Mandel SJ, Mazzaferri EL, McIver B, Pacini F, Schlumberger M, Sherman SI, Steward DL, Tuttle RM 2009 Revised American Thyroid Association management guidelines for patients with thyroid nodules and differentiated thyroid cancer: the American Thyroid Association (ATA) Guidelines Taskforce on Thyroid Nodules and Differentiated Thyroid Cancer. Thyroid 19:1167-1214.

2. Xing M, Haugen BR, Schlumberger M 2013 Progress in molecular-based management of differentiated thyroid cancer. Lancet 381:1058-1069.

3. Pacini F, Ito Y, Luster M, Pitoia F, Robinson B, Wirth L 2012 Radioactive iodine-refractory differentiated thyroid cancer: unmet needs and future directions. Expert Rev Endocrinol Metab 7:541-554.

4. Durante C, Haddy N, Baudin E, Leboulleux S, Hartl D, Travagli JP, Caillou B, Ricard M, Lumbroso JD, De Vathaire F, Schlumberger M 2006 Long-term outcome of 444 patients with distant metastases from papillary and follicular thyroid carcinoma: benefits and limits of radioiodine therapy. J Clin Endocrinol Metab 91:2892-2899.

5. Gruber JJ, Colevas AD 2015 Differentiated thyroid cancer: focus on emerging treatments for radioactive iodinerefractory patients. Oncologist 20:113-126.

6. Matsui J, Yamamoto Y, Funahashi Y, Tsuruoka A, Watanabe T, Wakabayashi T, Uenaka T, Asada M 2008 E7080, a novel inhibitor that targets multiple kinases, has potent antitumor activities against stem cell factor producing human small cell lung cancer H146, based on angiogenesis inhibition. Int J Cancer 122:664-671.

7. Matsui J, Funahashi Y, Uenaka T, Watanabe T, Tsuruoka A, Asada M 2008 Multi-kinase inhibitor E7080 suppresses lymph node and lung metastases of human mammary breast tumor MDA-MB-231 via inhibition of vascular endothelial growth factor-receptor (VEGF-R) 2 and VEGF-R3 kinase. Clin Cancer Res 14:5459-5465.

8. Okamoto K, Kodama K, Takase K, Sugi NH, Yamamoto Y, Iwata M, Tsuruoka A 2013 Antitumor activities of the targeted multi-tyrosine kinase inhibitor lenvatinib (E7080) against RET gene fusion-driven tumor models. Cancer Lett 340:97-103.

9. Lenvima (lenvatinib) [prescribing information]. Eisai, Inc., Woodcliff Lake, NJ, 2015.

10. Schlumberger M, Tahara M, Wirth LJ, Robinson B, Brose MS, Elisei R, Habra MA, Newbold K, Shah MH, Hoff AO, Gianoukakis AG, Kiyota N, Taylor MH, Kim SB, Krzy- zanowska MK, Dutcus CE, de las Heras B, Zhu J, Sherman SI 2015 Lenvatinib versus placebo in radioiodine-refractory thyroid cancer. N Engl J Med 372:621-630.

11. Brose MS, Nutting CM, Jarzab B, Elisei R, Siena S, Bastholt L, de la Fouchardiere C, Pacini F, Paschke R, Shong YK, Sherman SI, Smit JW, Chung J, Kappeler C, Pena C, Molnar I, Schlumberger MJ; DECISION Investigators 2014 Sorafenib in radioactive iodine-refractory, locally advanced or metastatic differentiated thyroid cancer: a randomised, double-blind, phase 3 trial. Lancet 384:319-328.

12. Worden F 2014 Treatment strategies for radioactive iodinerefractory differentiated thyroid cancer. Ther Adv Med Oncol 6:267-279.

13. Schlumberger M, Brose M, Elisei R, Leboulleux S, Luster M, Pitoia F, Pacini F 2014 Definition and management of radioactive iodine-refractory differentiated thyroid cancer. Lancet Diabetes Endocrinol 2:356-358.

14. Vaisman F, Carvalho DP, Vaisman M 2015 A new appraisal of iodine refractory thyroid cancer. Endocr Relat Cancer 22:R301-R310.

15. Eisenhauer EA, Therasse P, Bogaerts J, Schwartz LH, Sargent D, Ford R, Dancey J, Arbuck S, Gwyther S, Mooney M, Rubinstein L, Shankar L, Dodd L, Kaplan R, Lacombe D, Verweij J 2009 New response evaluation criteria in solid tumours: revised RECIST guideline (version 1.1). Eur J Cancer 45:228-247.

16. US Department of Health and Human Services; National Institutes of Health; National Cancer Institute 2009 Common Terminology Criteria for Adverse Events (CTCAE), version 4.0. NIH Publication No. 09-5410. Available at: https://evs.nci.nih.gov/ftp1/CTCAE/About.html (accessed October 7, 2016).

17. Kiyota N, Schlumberger M, Muro K, Ando Y, Takahashi S, Kawai Y, Wirth L, Robinson B, Sherman S, Suzuki T, Fujino K, Gupta A, Hayato S, Tahara M 2015 Subgroup analysis of Japanese patients in a Phase 3 study of lenvatinib in radioiodine-refractory differentiated thyroid cancer. Cancer Sci 106:1714-1721

18. Wassermann J, Bernier MO, Spano JP, Lepoutre-Lussey C, Buffet C, Simon JM, Ménégaux F, Tissier F, Leban M, Leenhardt L 2016 Outcomes and prognostic factors in radioiodine refractory differentiated thyroid carcinomas. Oncologist 21:50-58.

19. Rubino C, de Vathaire F, Dottorini ME, Hall P, Schvartz C, Couette JE, Dondon MG, Abbas MT, Langlois C, Schlumberger M 2003 Second primary malignancies in thyroid cancer patients. Br J Cancer 89:1638-1644.

20. Pryma DA, Mandel SJ 2014 Radioiodine therapy for thyroid cancer in the era of risk stratification and alternative targeted therapies. J Nucl Med 55:1485-1491.

Address correspondence to: Naomi Kiyota, MD, PhD

Department of Medical Oncology and Hematology Kobe University Hospital 7-5-1 Kusunoki-Cho Chuo-ku Kobe Hyogo Japan

E-mail:nkiyota@med.kobe-u.ac.jp 